\title{
THE INFLUENCE OF SELECTED FACTORS ON THE USE OF HERBAL PRODUCTS
}

\section{- Abdul Bashiru Jibril, Michael Adu Kwarteng, Miloslava Chovancova, Richard Denanyoh}

\begin{abstract}
Competitiveness associated with the herbal industry in both developed and developing countries is quickly gaining momentum, mainly because of the medicinal benefits incurred to customers. Alternatively, prior studies have shown that herbal product consumption in a developing country is largely centered on the tendency to substitute herbal products for remedies associated with modern medicine. Given the purported benefits associated with the use of herbal products from the perspective of developing countries, only a limited amount of studies have focused on the demographic inclination and use of herbal products in the developing world. The present research concentrates on the situation in Ghana with the goal of examining the influence of specific demographic features as well as the degree of product processing in terms of how consumer choice is affected. To this end, 250 self-administered questionnaires were distributed randomly to herbal consumers in the Jaman North District in the Bono Region of Ghana, out of which 207 valid responses were analyzed using a nonparametric test. Our findings revealed that gender, age, and occupation have no positive relationship to the use of an herbal product. However, both consumers' educational level and the degree of product processing have a significant positive relationship regarding the choice of using herbal product. The present study not only adds to the literature, but offers an empirical understanding of Ghanaian consumer characteristics regarding herbal product consumption to aid production and marketing entities in establishing and sustaining competitive advantages.
\end{abstract}

Keywords: competitiveness, demographic factors, herbal product, correlation, degree of processing, Ghana JEL Classification: M2; M21; M31.

Received: November, 2018

1st Revision: October, 2019

Accepted: November, 2019

\section{INTRODUCTION}

Herbal products are described as medicines (remedies) derived from plants. These products are largely used as supplements to improve health and well-being as well as for other therapeutic purposes. Herbal products are available as tablets, capsules, powders, extracts, teas, among others. 
Interestingly, the production and consumption of these products have boosted both the global and local herbal market (Verma \& Singh, 2008). The herbal product industry is undeniably a lucrative business in the world market today, with countries such as China, India, Singapore, and Malaysia having some portion of total economic revenue generated from this industry. These countries and many others have made great investments in their herbal research industries with the view of boosting their overall economies (Brown, 1999; Kotler \& Gertner, 2002).

The competitive advantage of using herbal products has shifted gradually over the years from synthetic to herbal medicine usage in a move which could be described as "Return to Nature." Medicinal plants have been known for ages and are highly valued all over the world as a rich source of natural prevention of and cures for diseases and ailments (Samiee et al., 2005; Sharma et al., 2008). Ayurvedic herbal drugs are widely known to be popular among the rural and urban communities of India (Samiee et al., 2005). The demand for plant-based medicines, food supplements, cosmetics, and other applications of herbal products are increasing in both developing and developed countries due to the growing recognition of their efficacy as well as due to economic benefits (Bazrafshani et al., 2019). According to Semenya et al., (2012) a revival of interest in herbal-based medicine is taking place due to the increasing number of the health hazards associated with the indiscriminate use of modern allopathic treatments and medicines.

The effective uses of herbal products have been recognized for centuries in what has been termed indigenous systems of medicine (Pal \& Shukla, 2003; Zheng et al., 2019). While the extant literature has shown that some herbal medicines may have adverse, even severe consequences, they are now in even greater demand in the developing world for use in primary healthcare. The natives of these countries use it not only because these substances are far less expensive, but also because these systems enjoy greater cultural acceptability, better compatibility with the human body, and bring on minimal side effects compared to non-herbal medicines and treatments. Similarly, most herbal products on the market today have received substantial attention from scholars and practitioners regarding the demand and usefulness of these products (Pal \& Shukla, 2003; Pan et al., 2014). The availability of plant products has been exploited with varying success to cure and prevent diseases throughout history (Raskin et al, 2002). Due to the side effects of some synthetic products, herbal products are gaining popularity in the world market and it has been noted that one major reason for their popularity and acceptability is the belief that all-natural products are safe (Zheng et al., 2019; Elvin-Lewis, 2001; Patwardhan et al., 2004).

With respect to the growing interest in herbal medicine, a sizable number and a wide range of research works and publications have been authored on various topics and issues in line with the use of the herbal products. Yet, to the present authors' knowledge, no work so far has attempted to delve into the strength of association between consumer characteristics, the degree of product processing, and the use of the herbal products in a developing country like Ghana. The scant but few available literature reviews have been conducted by concentrating merely on the human uses of an herbal product and the benefits of the product and the studies have been centered only in specific areas in sub-Saharan Africa. For instance, Makunga et al. (2008), as well as have reported on different reviews of literature on herbal product usage in South Africa while Kairu et al. (2013) conducted a reflective analysis of how in recent times herbal medicinal products that cure heart-related diseases are disappearing from the forest zone in West Africa. 
The methodological approaches used in previous review articles conducted on herbal product utilization are dissimilar from what this paper proposes. This study seeks to add to existing literature and fill research gaps in the following ways: (1) Does gender, age, education and occupation positively relate to the usage of the herbal product? and (2) Does the degree of processing of herbal products positively relate to the usage of herbal products? These questions seek to remedy the paucity of available researches geared towards consumer preference of local herbal products within a developing economy, although it would here be appropriate to recognize that the herbal industry also has market potential in terms of job creation and revenue generation for a country as a whole (Alkhateeb et al., 2006). This study, therefore, aims to establish the relationship between gender, age, education, occupation, degree of processing, and herbal product usage among Ghanaian herbal consumers. This article will explore areas of the herbal market as well as the academic literature. The theoretical benefit of this study would be to widen the scope of consumer behavior regarding the dynamics of demographic variables and their effect on herbal product consumption in the marketing discipline. The subsequent parts of this paper are as follows: literature review, methodology, results and discussion, conclusion, and recommendation for future studies.

\section{RELATED WORKS}

\subsection{Global market progress of herbal products}

Globalization has led to the creating and expanding opportunities for the production and marketing of numerous products from both within and among developing and underdeveloped economies. For example, China's food and textile industry as well as medicinal herbal products businesses have greatly expanded export in the international market (Rath, 2005; Van Andel et al., 2012). Countries that are dominant or ascendant in the growing herbal industry have experienced situations such as an increase in the export and import of raw drugs (herbal products), a rise in domestic and foreign business in traditional medicines produced from raw green plants, a significant rise in clinical research to determine biochemical results as well as market studies to track consumer purchasing patterns, a significant increase in the patents of herbal products. (Kumar \& Janagam, 2011). In recent decades, reports have come indicating an increase in the interest of western populations in herbal medicine, especially of western scientists. Most of their research into medicinal plants was tailored towards developing and underdeveloped countries so as to strategize and develop more effective and safe herbal products for its concern to both consumers and marketers (Tomlinson, \& Akerele, 2015).

Additionally, the worldwide consumption pattern of herbal products has seen a remarkable change during the middle of the last century. However, by extension, it is interpreted to mean that demand and use of herbal products have increased dramatically over time now with a projected increase in the coming years. Statistically, it has been reported that the global herbal medicine market size was valued at USD 71.19 billion in 2016 and is projected to show a profitable or appreciable growth over the forecast period (Aneesh et al., 2009). The increase is attributed to the increasing preference of consumers towards traditional medicines (Ayurveda, Unani and Traditional Chinese Medicine). These products are well-known in the Indian herbal industry and 
also in the world market with a minimal side effect (Pandey et al., 2017). To add, it has been estimated that an increase in substantial research investments and funding will support the growth of the herbal market in the coming years.

However, it is known that the global plant-derived products market is expected to gain momentum over the projected period due to the low cost of herbal medicines compared to modern medicine. These drugs are witnessing significant progress at the global level. For example, in China, the intervention of these drugs has helped to remedy acute respiratory syndrome (SARS) (Lu Wang \& Xiong Chen, 2004). The less expensive nature of these herbal products has increased the preference for cost-effective treatment alternative for various medical conditions such as cold \& cough, kidney disorders, digestive problems, and chest congestion is anticipated to enhance the further acceptance of these medicine forms worldwide (Balabanis et al., 2001; Watson \& Wright, 2000).

Moreover, herbal treatment constitutes an important aspect of most health delivery systems in Africa for that matter in some parts of the world today (WHO report). For example, China, India, and Singapore have made a greater impact on the Asian and African markets with most of their herbal products. Apart from giving identity to the nation through its brand and potency, the herbal product identifies an individual company as to its area of specialization in terms of health delivery (Thongruang, 2008). The fact that consumers in Ghana have traditionally used herbal/ traditional remedies to treat common ailments has given rise to the demand for branded herbal/ traditional products. The medicinal plants traded at the market were mostly used for various purposes including women's health, in rituals, as aphrodisiacs, and against sexually transmitted diseases. As a matter of fact, herbal medicine has been used alongside modern medicine in Ghana and many continue to rely on it for their healthcare despite the increasing use of modern medicine. The product has played a significant role in healthcare delivery for a long time. Studies have shown that approximately $80 \%$ of the world's population, $80 \%$ of the people in developing countries, $80 \%$ of Africans and about $70 \%$ to $75 \%$ of the population of Ghana rely on herbal medicine for their primary healthcare (Jibril, 2017; Van Andel et al., 2012). However, there are no studies regarding the association of consumers' demographics and the use of the product in Ghana, hence this present study focuses on that objective.

\subsection{Consumers' demographics and degree of herbal product processing}

Demographics describe a population in terms of its size, distribution, and structure. It measures aspects of the population such as age, gender, or year of birth. For example, social class factors, especially occupation and education, usually have an influence on buying intention of a product group such as family. Technically, brand preference reflects a desire to use a particular company's products or services, even when there are equally priced and equally-available alternatives. By extension, it is important to companies because it provides an indicator of their customers' loyalty, the success of their marketing tactics, and the strength of their respective brands.

Consumer' Age: This variable has been investigated extensively by many scholars and some of them debated that young people (especially youth) are most likely to be delicate to herbal market issues. Notwithstanding, several studies over the last two decades identified the green consumer has been older than the average (Straughan \& Roberts, 1999). As a matter of fact, the relationship 
that exists between the age and other variables has also been explored by other authors with varied interpretation (results contradictory). Some authors found non-significant relations between the age and use of the product (Straughan \& Roberts, 1999) while others observe a significant and positive relation (Akehurst et al., 2012).

Consumer's gender: Also, several authors have examined the influence of gender on herbal consumer behavior. In spite of the fact that many women are more conscious and friendly in the green environment, there has not been extensive elaboration from authors who studied the variable, hence results in the literature is not conclusive (Han et al., 2011; Straughan \& Roberts, 1999; Valtonen et al., 2010)

Consumer's education: Most studies that include the educational level of consumers have indicated a positive relationship with green consumer attitude (Laroche et al., (2001); D’Souza et al., (2007); Han et al., (2011). In view of this, it suggests that consumers with a high level of education are more sensitive and conscious in the green market and tend to act accordingly. However, in the works of (Pal \& Shukla, 2003; Straughan \& Roberts, 1999), it was observed that education have a positive relationship with green consumer behavior and intention.

Consumer's occupation: According to Awad (2011); Kim (2011) and Roberts (1996), consumers' socio-economic status (occupation) was usually perceived to have a positive relation to green consumer behavior and intention. This is based on the general assumption that improved a high standard of green product calls for a higher price in the green market and vice-versa (Anderson Jr \& Cunningham, 1972). In this regard, authors from the various surveys took note of this variable in their empirical analysis. However, results are not always convincing (Akehurst et al., 2012).

Additionally, the degree of herbal products processing describes or indicates the level of the usable product which ultimately determines the importance of the product in the hearts and minds of customers. In other words, it represents which category of the herbal product is preferred under assumptions of equality in price and availability. With respect to the herbal product, the definition used in this context, particularly in this study, assumes the category or stage of production of herbal product. This stage includes (1) raw-state (unprocessed) products, (2) semi-processed products and (3) fully-processed products. A study has shown that the degree or level of a life cycle regarding consumption does influence customers' purchase intention (Jibril et al., 2019).

\subsection{Hypotheses development}

The research model depicts the demographic characteristics of customers interested in the herbal product. It shows how the variables; gender, consumer's age, consumer's educational level, consumer's occupation, and degree of processing relate to the herbal product use. This could be shown in Figure 1. To achieve this goal, we developed propositions to establish relationships with respect to a mutual association of the herbal product regarding its use. In doing so, the following hypotheses were set;

H1: The use of the herbal product is positively correlated with the consumer's gender.

H2: The use of the herbal product is positively correlated with the consumer's age.

H3: The use of the herbal product is positively correlated with the consumer's educational level. 
H4: The use of the herbal product is positively correlated with the consumer's occupation.

H5: The degree of herbal product processing is positively correlated with the herbal product use.

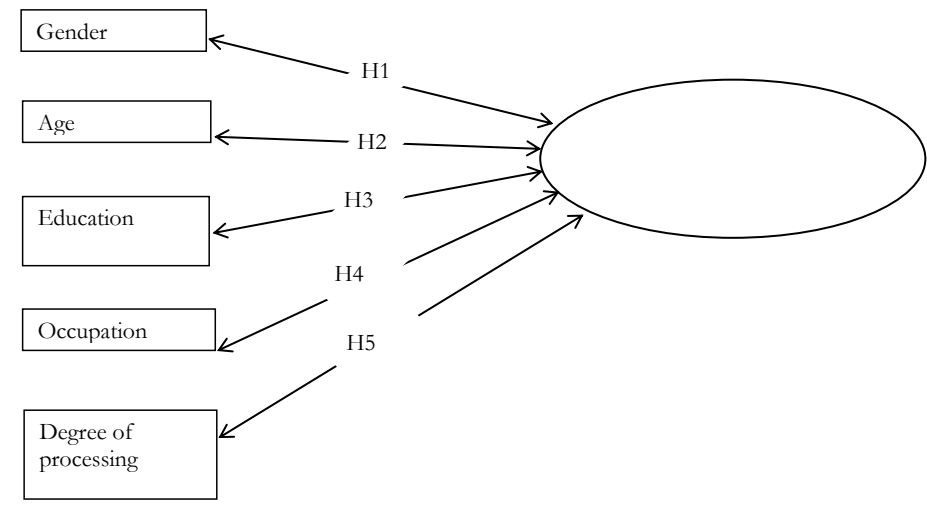

Fig. 1 - A correlation model. Sources: own research

\section{METHODOLOGY}

\subsection{Surveyed data}

Since the study was based on a quantitative inquiry, we developed a structured questionnaire to gather primary data from users of the herbal products in Ghana. Also, since the study targeted respondents from rural Ghana, a self-reporting questionnaire was designed to intercept customers at various herbal product shops in the Jaman North District of Bono region of Ghana. For the purpose of achieving the stated hypotheses, a convenient sampling technique was employed. Among others, geographical proximity, population size, accessibility and affordability in terms of cost were considered in selecting this technique (Warner, 1965).

The data collection lasted between January to February 2019. Out of 250 questionnaires administered, only 207 responses were valid for the analyses representing the eighty-three percent response rate. However, with respect to the data analysis technique, non-parametric tests precisely the spearman's correlation rs and chi-square tests $(\mathrm{x} 2)$ were employed for the analysis. By virtue of this knowledge, data was implemented in three different phases: firstly, the demographic profiling of consumers, then, the chi-square test of the demographic variables, and lastly, the test of Spearman's r correlation among the variables. A summary of respondents' data is indicated in Table 1 below.

Tab. 1 - Demographic profile of respondents. Source: own research

\begin{tabular}{|l|l|l|}
\hline Demography & Frequency & Percentage (\%) \\
\hline Gender & & \\
Male & 104 & 104 \\
Female & 94 & 94 \\
Prefer not to say & 9 & 9 \\
\hline
\end{tabular}




\begin{tabular}{|l|l|l|}
\hline Consumer's Age & & \\
$<20$ & 16 & 7.7 \\
$21-30$ & 78 & 37.7 \\
$31-40$ & 47 & 22.7 \\
$41-50$ & 39 & 18.8 \\
$>51$ & 27 & 13.0 \\
\hline Consumer's Education Level & & \\
None & 55 & 26.6 \\
Basic/high & 75 & 36.2 \\
Undergraduate & 46 & 22.2 \\
Postgraduate & 31 & 18.8 \\
\hline Consumer's Occupation & & \\
Student & 49 & 23.7 \\
Formal sector & 51 & 24.6 \\
Informal sector & 68 & 32.9 \\
Other & 39 & 18.8 \\
\hline Use of Herbal Product & & \\
Yes & 115 & 55.6 \\
No & 41 & 19.8 \\
Maybe & 51 & 24.6 \\
\hline
\end{tabular}

\subsection{Variable measurement}

With respect to demographic characterization, the pioneers in studying the demographic factors (gender, age, education, and occupation) related to this theme were executed by Anderson Jr \& Cunningham (1972), Berkowitz \& Lutterman, (1968), Roberts (1996) while measurement of 'degree of processing' of the herbal product took inspiration from Sharma et al. 2008. Their studies espouse how individual characteristics predict or influence the usage intention towards herbal products. In the same analysis, there was indicated a typical green consumer in terms of gender as a female with the average age of 40, complement with a high level of education and socioeconomic status (occupation) above average. Similarly, other research in the same domain showed that women were seen as more conscious in the green market than men, but men were willing to pay more irrespective of the product brand in a typical herbal market (D'Souza et al., 2007). However, all these previous works could not highlight the specific product of focus within the herbal market. Also, the work of this nature has not been done in the context of Africa like Ghana. In view of this, the present study focuses on the following demographic variables in the analysis: gender, age, education, and occupation as well as degree of processing of the herbal product.

\section{RESULTS AND DISCUSSION}

\subsection{Statistical analysis of demographic variables}

The empirical data from the field using IBM SPSS shows a varied interpretation regarding the 
demographic outlook of the consumers. In view of this, the frequency of demographic characteristics indicated in Table 1 suggest that most consumers (50.5\%) are male users of herb products in the Ghanaian herbal market. Also, most (37.7\%) of consumers between the ages of 21 to 30 liked the use of herbal products relative to other age categories in this survey. Also, the research showed that most $(36.2 \%)$ of the sampled respondents are within the bracket of junior and high school certificate while a moderate $(26.6 \%)$ do not have any formal education. The study further inquired about the occupational level of the users of the herbal products and it was indicated that most $(32.9 \%)$ of the consumers are engaged in the informal sector and nearly 19 percent belong to another category of income-earning activities. However, a substantial number of students $(23.7 \%)$ also confirmed to use the herbal products.

\subsubsection{Goodness of fit test}

For the purpose of this analysis, the chi-square test sought to evaluate the association and the dependence of demographic factors (gender, age, education, and occupation) on the use of the herbal product (dependent variable). Also, this technique further explores the association between any two given attributes regarding the cause-and-effect relationship. The test revealed that gender disparities have significant evidence in determining the use of green products in the herbal industry. With the statistical analysis in Table 2, the asymptotic significance (2-sided) represents the $\mathrm{p}$-value of the measured variable. By virtue of this computation and interpretation, the $\mathrm{p}$-value of $0.024(\mathrm{p}<0.05)$ suggests that the chi-square test $(\mathrm{X} 2=11.211 \mathrm{a})$ is suitable in determining the relationship or association between the independent variables (gender, age, education, occupation, and degree of processing) towards the use of the herbal product (dependent variable). Therefore, Table 2 shows the estimation of the model fit.

Tab. 2 - Chi-Square Test. Source: own research

\begin{tabular}{|l|l|l|l|}
\hline & Value & df & Asymptotic Significance (2-sided) \\
\hline Pearson Chi-Square & $11.211^{\mathrm{a}}$ & 4 & .024 \\
\hline Likelihood Ratio & 11.304 & 4 & .023 \\
\hline Linear-by-Linear Association & 1.419 & 1 & .234 \\
\hline N of Valid Cases & 207 & & \\
\hline
\end{tabular}

Moreover, the technique deduced a symmetric measure (Table 3) indicating nominal by nominal values (Phi and Cramer's V). The phi and Cramer's values describe the strength of the relationship among the measured variables. With our computation of phi (0.233) and Cramer's (0.165), they indicate the size of the effect, hence the independent variables have a small-to-moderate effect on the use of the herbal product among sampled respondents. However, since the 2-cells $(22.2 \%)$ are greater than 20 percent by the chi-square rule, suggesting that our assumption is varied, another action should be taken (Table 4). To this end, the chi-square test in this context could not be justified or satisfied with the statistical inferences from the data collected (Higgins $\&$ Koch, 1977). We proceeded to run a correlation test for conformity of the chi-square test (Table 3). 
Tab. 3 - Symmetric Measures. Source: own research

\begin{tabular}{|l|l|l|}
\hline & Value & Approximate Significance \\
\hline Nominal by Nominal Phi & .233 & .024 \\
Cramer's V & .165 & .024 \\
N of Valid Cases & 207 & \\
\hline
\end{tabular}

\subsubsection{Correlation test}

The aim of this subsequent test is to evaluate the extent of the relationship between the likeness of herbal products and the demographic factors of the consumers. Table 4 shows the statistical relationship (correlation coefficient) of the constructs (demographic factors) against the like and use of the herbal product. Meanwhile, readers should note that the strength of the correlation coefficient ranges from -1 to +1 . For detail understanding, the correlation coefficient with a negative sign indicates an indirect relationship between the predictive and the comparable variables whilst the positive values indicate a direct strength between the predictive and the control variables. The results from the Spearman's correlation coefficient (rs) table (Table 4) depicts the statistical strength of how the demographic factors relate and determine the likeness and use of the herbal product.

Tab. 4 - Correlation Coefficient Matrix. Source: own research

\begin{tabular}{|l|l|l|l|l|l|l|}
\hline & 1 & 2 & 3 & 4 & 5 & 6 \\
\hline 1.Gender & 1.00 & & & & & \\
\hline 2.Age & $.208^{* *}$ & 1.00 & & & & \\
\hline 3.Educational Status & .011 & $.626^{* *}$ & 1.00 & & & \\
\hline 4.Occupation & .342 & -.264 & $.430^{* *}$ & 1.00 & & \\
\hline 5.Brand preference & 0.531 & 0.333 & 0.722 & $0.564^{* *}$ & 1.00 & \\
\hline 6.Use of Herbal Product & -.108 & -.046 & .081 & -.206 & $0.751^{* *}$ & 1.00 \\
\hline
\end{tabular}

$* *$ p values $<0.05$ significant. Level

Tab. 5 - Hypothesized relationships. Source: own research

\begin{tabular}{|l|l|l|}
\hline Relationships & Spearman's rs & Remarks \\
\hline Consumer's gender $\leftrightarrow$ herbal product usage & -0.108 & Not significant \\
\hline Consumer's age $\leftrightarrow$ herbal product usage & -0.046 & Not significant \\
\hline Consumer's education $\leftrightarrow$ herbal product usage & 0.081 & Not significant \\
\hline Consumer's occupation $\leftrightarrow$ herbal product usage & -0.206 & Not significant \\
\hline Degree of processing $\leftrightarrow$ herbal product usage & $0.751 * *$ & Significant \\
\hline
\end{tabular}

$*^{* *}$ p values $<0.05$ significant. Level

Interestingly, the results from the correlation coefficient matrix show a contrary view regarding the three hypotheses. The correlated independent variables (education and brand preference) and their respective coefficients indicate a positive relationship with respect to the comparable 
variable (herbal product usage) for the exception of gender, age, and occupation variables of the respondents with $-0.108,-0.046$, and -0.206 respectively, results which show no positive relationship with the use of herbal products. Even though educational level had an overall positive relationship (0.081) with the use of the herbal product, it has a small or weak influence on the use of herbal products in the Ghanaian herbal market. Nevertheless, our results show that the brand preference variable shows a positive and significant relationship with the use of herbal products among Ghanaian herbal consumers. This suggests that herbal product characteristics like rawstate, semi-processed, and fully-processed largely influence positively from the consumers' point of view. It is worth understanding, however, that the estimates in bold shown in the diagonal borders in the correlation matrix indicate the magnitude of relationship among the variables (constructs) observed. Therefore, to draw inferences from the analysis, readers should note that the general understanding of Table 4 and Appendix A is to observe the coefficient (strength of relationship) among the attributes which emerge from the analyses. Again, in Table 5, readers should note that from the statistical point of view, the association between brand preference and the use of herbal products $\left(0.751^{* *}\right)$ is statistically significant per our analyses at p-value $<0.05$. Though from a researcher's point of view, the consumer's educational level indeed has a positive relationship with the use of herbal products $(0.081)$, yet, it was shown to be insignificant from a statistical point of view. At the same time, the researchers have also shown the strength of correlated variables in a percentage form (Table 6)

The present analysis has taken into account the degree of processing of herbal products with respect to the age of consumers in the herbal market. It was indicated that the majority of users of the product ranging between the age of 41 to 50 prefer to purchase the herbal product in a raw-state (unprocessed), while other age groups prefer to use processed herbal products so as to enjoy convenience and to accelerate the rate of product efficacy.

In practice, the analysis suggests that producers and marketers of herbal products should go the extra mile in terms of product redesign and packaging so as to meet the target market based on this study outcome. Still, in cross-checking our hypotheses which were stated earlier, the following evidence was discovered from the current survey;

H1: The use of the herbal is positively correlated with the consumer's gender in the Ghanaian herbal market.

These results disprove the hypothesis of our present study and confirm the evidence from previous studies conducted by (Han et al., 2011; Valtonen et al., 2010), although our present results do corroborate the work of (Straughan \& Roberts, 1999) which indicate that gender does not play a significant role in green consumer behavior. Therefore, the hypothesis that "The use of the herbal is positively correlated with consumer's gender in the Ghanaian herbal market" finally cannot be accepted.

H2: The use of the herbal product is positively correlated with the consumer's age in the Ghanaian herbal market.

This hypothesis was also not upheld by the present study, and our results do agree with the empirical works of Akehurst et al., (2012). Therefore, the hypothesis that "The use of the herbal product is positively correlated with consumer's age in the Ghanaian herbal market” finally cannot be accepted. 
H3: The use of the herbal product is positively correlated with the consumer's educational level in the Ghanaian herbal market.

Similarly, our empirical evidence corroborates the stated hypothesis, which further agrees with the claims by Han et al., (2011), Laroche et al., (2001) that education has a positive relationship with green consumer behavior. Therefore the hypothesis that "the use of the herbal product is positively correlated with the consumer's occupation in the Ghanaian herbal market" can be accepted.

H4: The use of the herbal product is positively correlated with the consumer's occupation in the Ghanaian herbal market.

Our results did not support this hypothesis, and also did not agree with the empirical evidence from Anderson Jr \& Cunningham, (1972), Roberts (1996) as well as Straughan \& Roberts (1999) that the socio-economic status of green consumers always has a positive influence on their attitudes and intentions regarding herbal products. Therefore, the hypothesis in the present study that "the use of the herbal product is positively correlated with the consumer's occupation in the Ghanaian herbal market” cannot be accepted.

H5: The degree of processing is positively correlated with the use of the herbal product in the Ghanaian herbal market.

Estimates from the present study show that the degree of processing as a determinant variable has a positive consequence for the production and marketing of herbal products. From our point of view, the evidence suggests that users of herbal products consider the production stage of the product before they demonstrate their willingness to use such a product. This work corroborates the earlier studies of Rekha, \& Gokila (2015) and that of Nagananthi \& Mahalakshmi (2016) which have affirmed the positive impact of product-state (degree of processing) as an influential variable in the use of an herbal product in the Ghanaian market.

\section{CONCLUSION}

The goal of this study has been to establish the relationship between gender, age, education, occupation, degree of processing, and herbal product usage among Ghanaian herbal consumers. Among the consumer features considered in this article are gender, age, education, occupation, and herbal-product-state (degree of processing). To execute this objective, 250 self-administered questionnaires were distributed to herbal consumers in the Jaman North District in the Bono Region of Ghana, out of which 207 valid responses were analyzed using a non-parametric test.

The data show differentiating interpretations regarding the demographic outlook of consumers. In the frequency table of demographic characteristics shown in Table 1, it is evident that most $(50.5 \%)$ of the dominant users of herbal products in the Ghanaian herbal market are males. The youthful population was indicated as showing the highest number of users of products in the herbal market. The findings from a non-parametric test (Spearman's rho) revealed that demographic factors (gender, age, and occupation) have no positive relationship with the use of herbal products. Though the correlation coefficient of education $(\mathrm{rs}=0.081)$ within Spearman's correlation coefficient matrix a positive association was depicted, but results suggest a weak relationship 
in terms of consumer willingness to use the products. Nevertheless, the herbal-product-state (herein referred to as 'degree of processing') indicates a strong positive and significant relationship with the increased use of herbal products.

The practical implication of this study provides insights into both established and emerging herbal firms, especially in developing countries in terms of how they can best establish and maintain market share within today's hugely competitive herbal products industry. Certainly, the theoretical benefit for this study would widen the overview of the scope of consumer behavior as well as supplement previous demographic marketing analyses. Especially because consumers exhibit varied and ever-changing tastes and preferences for particular products, it is imperative for firms to understand the behavior of consumers to enable the companies to strategize and respond to fluctuating market demands to remain competitive. Moreover, this current study further expands the examination of consumer behavior, as our empirical analyses supplement and complement other studies.

With regard to marketing, the paper contributes to the knowledge of consumer behavior in the green market, specifically in the herbal segment, especially in regard to understanding demographic impacts of consumers. This knowledge could inform both scholars and managers.

Still, a number of limitations must be kept in mind. First, since the study considers only respondents in rural Ghana, readers should be cautious regarding the generalization of the current research to those outside rural areas in Ghana or other sub-Saharan African regions. Second, the study is limited by its small sample size, the results of which do not reflect the entire population of rural Ghana.

Regarding forthcoming research on the consumption of herbal products, the author recommends that future studies take in a wider scope of respondents and even multiple regions. Moreover, other demographic variables could be researched to enhance the present findings. Lastly, cross-country cultural analyses of this kind are highly valuable, thus future researchers might consider developing a cross-sectional study in order to compensate for disparities among population distribution.

Acknowledgments

This work was supported by the Internal Grant Agency of FaME through TBU in Zlín No. IGA/ FaME/2019/008; Project title: Country-of-origin effect on the domestic product (brand) purchasing intention and SME's sustainability in developing countries.

\section{References}

1. Akehurst, G., Afonso, C., \& Martins Gonçalves, H. (2012). Re-examining green purchase behaviour and the green consumer profile: new evidences. Management Decision, 50 (5), 972-988. https://doi.org/10.1108/00251741211227726

2. Alkhateeb, F. M., Doucette, W. R., \& Ganther-Urmie, J. M. (2006). Influences on consumer spending for herbal products. Research in Social and Administrative Pharmacy, 2 (2), 254-265. https://doi.org/10.1016/j.sapharm.2006.03.001

3. Anderson Jr, W. T., \& Cunningham, W. H. (1972). The socially conscious consumer. Journal of Marketing, 36 (3), 23-31. https://doi.org/10.1177/002224297203600305 
4. Aneesh, T., Hisham, M., Sekhar, M., Madhu, M., \& Deepa, T. (2009). International market scenario of traditional Indian herbal drugs-India declining. International Journal of Green Pharmacy, 3 (3), 184. https://doi.org/10.4103/0973-8258.56271

5. Awad, T. A. (2011). Environmental segmentation alternatives: buyers' profiles and implications. Journal of Islamic Marketing, 2 (1), 55-73. https://doi. org $/ 10.1108 / 17590831111115240$

6. Balabanis, G., Diamantopoulos, A., Mueller, R. D., \& Melewar, T. C. (2001). The impact of nationalism, patriotism and internationalism on consumer ethnocentric tendencies. Journal of International Business Studies, 32 (1), 157-175. https://doi.org/10.1057/palgrave.jibs.8490943

7. Bazrafshani, M. S., Khandani, B. K., Pardakhty, A., Tajadini, H., Afshar, R. M. P., Moazed, V., \& Sharifi, H. (2019). The prevalence and predictors of using herbal medicines among Iranian cancer patients. Complementary therapies in clinical practice, 35, 368-373.

8. Berkowitz, L., \& Lutterman, K. G. (1968). The traditional socially responsible personality. Public Opinion Quarterly, 32 (2), 169-185. https://doi.org/10.1086/267597

9. Brown, S. (1999). Retro-marketing: yesterday's tomorrows, today! Marketing Intelligence \& Planning, 17 (7), 363-376. https://doi.org/10.1108/02634509910301098

10. D’Souza, C., Taghian, M., Lamb, P., \& Peretiatko, R. (2007). Green decisions: demographics and consumer understanding of environmental labels. International Journal of Consumer Studies, 31 (4), 371-376. https://doi.org/10.1111/j.1470-6431.2006.00567.x

11. Elvin-Lewis, M. (2001). Should we be concerned about herbal remedies? Journal of Ethnopharmacology, 75 (2-3), 141-164. https://doi.org/10.1016/S0378-8741(00)00394-9

12. Han, H., Hsu, L.-T. J., Lee, J.-S., \& Sheu, C. (2011). Are lodging customers ready to go green? An examination of attitudes, demographics, and eco-friendly intentions. International Journal of Hospitality Management, 30 (2), 345-355. https://doi.org/10.1016/j.ijhm.2010.07.008

13. Higgins, J. E., \& Koch, G. G. (1977). Variable selection and generalized chi-square analysis of categorical data applied to a large cross-sectional occupational health survey. International Statistical Review/Revue Internationale de Statistique, 45 (1), 51-38. https://doi. org/10.2307/1403003

14. Jibril, A. B. (2017). Projekt na posílení prodeje značkových rostlinných produktů Konate Herbal Center v Ghane.

15. Jibril, A. B., Kwarteng, M. A., \& Chovancova, M. (2019). A Demographic Analysis of Consumers' Preference for Green Products. International Scientific Conference CONTEMPORARY ISSUES IN BUSINESS, MANAGEMENT AND ECONOMICS ENGINEERING'2019, 9-10 May 2019, Vilnius, Lithuania. https://doi.org/10.3846/ cibmee.2019.044

16. Kairu, A., Gichuki, N., Kanya, J., \& Kindt, R. (2013). Disappearing medicinal plants in mt. kenya forests, kenya: a case study of east african green heart (Warburgia ugandensis sprague). Topclass Journal of Herbal Medicine, 2 (7), 159-165.

17. Kim, Y. (2011). Understanding green purchase: The influence of collectivism, personal values and environmental attitudes, and the moderating effect of perceived consumer effectiveness. 
18. Kotler, P., \& Gertner, D. (2002). Country as brand, product, and beyond: A place marketing and brand management perspective. Journal of Brand Management, 9 (4), 249-261. https://doi.org/10.1057/palgrave.bm.2540076

19. Kumar, M. R., \& Janagam, D. (2011). Export and import pattern of medicinal plants in India. Indian Journal of Science and Technology, 4 (3), 245-248.

20. Laroche, M., Bergeron, J., \& Barbaro-Forleo, G. (2001). Targeting consumers who are willing to pay more for environmentally friendly products. Journal of Consumer Marketing, 18 (6), 503-520. https://doi.org/10.1108/EUM0000000006155

21. Lu Wang, C., \& Xiong Chen, Z. (2004). Consumer ethnocentrism and willingness to buy domestic products in a developing country setting: testing moderating effects. Journal of Consumer Marketing, 21 (6), 391-400. https://doi.org/10.1108/07363760410558663

22. Makunga, N. P., Philander, L. E., \& Smith, M. (2008). Current perspectives on an emerging formal natural products sector in South Africa. Journal of Ethnopharmacology, 119 (3), 365-375. https://doi.org/10.1016/j.jep.2008.07.020

23. Nagananthi, T., \& Mahalakshmi, M. (2016). Consumers' brand preference and buying behaviour of cosmetic products at Coimbatore City. Intercontinental Journal of Marketing Research Review, 4 (1), 12-19.

24. Pal, S. K., \& Shukla, Y. (2003). Herbal medicine: current status and the future. Asian Pacific Journal of Cancer Prevention, 4 (4), 281-288.

25. Pan, S. Y., Litscher, G., Gao, S. H., Zhou, S. F., Yu, Z. L., Chen, H. Q., Znahng, S. F., Tang, M. K., Sun, J. N., \& Ko, K. M. (2014). Historical perspective of traditional indigenous medical practices: the current renaissance and conservation of herbal resources. Evidence-Based Complementary and Alternative Medicine. https://doi.org/10.1155/2014/525340

26. Pandey, P., Singh, S., \& Dalla, S. A. (2017). Conceptual Framework of Relationship Between Promotional Tools \& Consumer Buying Behavior. International Education and Research Journal, 3 (5). 107-109.

27. Patwardhan, B., Vaidya, A. D. B., \& Chorghade, M. (2004). Ayurveda and natural products drug discovery. Current Science, 86 (6), 789-799.

28. Raskin, I., Ribnicky, D. M., Komarnytsky, S., Ilic, N., Poulev, A., Borisjuk, N., Brinker, A., Moreno, D. A., Ripoll, Ch., Yakoby, N, O'neal, J. M., Cornwell, T., Pastor, I., \& Fridlender, B. (2002). Plants and human health in the twenty-first century. TRENDS in Biotechnology, 20 (12), 522-531. https://doi.org/10.1016/S0167-7799(02)02080-2

29. Rath, B. (2005). Globalization, global trend in herbal market, and the impact thereof on medicinal plants in Orissa. Vasundhara. Bhubaneswar.

30. Rekha, M. B., \& Gokila, K. (2015). A study on consumer awareness, attitude and preference towards herbal cosmetic products with special reference to Coimbatore City. International Journal of Interdisciplinary and Multidisciplinary Studies, 2 (4), 96-100.

31. Roberts, J. A. (1996). Green consumers in the 1990s: profile and implications for advertising. Journal of Business Research, 36 (3), 217-231. https://doi.org/10.1016/01482963(95)00150-6 
32. Samiee, S., Shimp, T. A., \& Sharma, S. (2005). Brand origin recognition accuracy: its antecedents and consumers' cognitive limitations. Journal of International Business Studies, 36 (4), 379-397. https://doi.org/10.1057/palgrave.jibs.8400145

33. Semenya, S., Potgieter, M., Tshisikhawe, M., Shava, S., \& Maroyi, A. (2012). Medicinal utilization of exotic plants by Bapedi traditional healers to treat human ailments in Limpopo province, South Africa. Journal of ethnopharmacology, 144 (3), 646-655. https://doi. org/10.1016/j.jep.2012.10.005

34. Sharma, A., Shanker, C., Tyagi, L. K., Singh, M., \& Rao, C. V. (2008). Herbal medicine for market potential in India: an overview. Academic Journal of Plant Sciences, 1 (2), 26-36.

35. Straughan, R. D., \& Roberts, J. A. (1999). Environmental segmentation alternatives: a look at green consumer behavior in the new millennium. Journal of Consumer Marketing, 16 (6), 558-575. https://doi.org/10.1108/07363769910297506

36. Thongruang, C. (2008). Consumer purchasing behavior for herbal medicine in drugstores in Bangkok. Naresuan University Journal: Science and Technology (NUJST), 16 (3), 195-202.

37. Tomlinson, T. R., \& Akerele, O. (Eds.). (2015). Medicinal plants: their role in bealth and biodiversity. USA: University of Pennsylvania press.

38. Valtonen, A., Markuksela, V., \& Moisander, J. (2010). Doing sensory ethnography in consumer research. International Journal of Consumer Studies, 34 (4), 375-380. https://doi. org/10.1111/j.1470-6431.2010.00876.x

39. Van Andel, T., Myren, B., \& Van Onselen, S. (2012). Ghana's herbal market. Journal of Ethnopharmacology, 140 (2), 368-378. https://doi.org/10.1016/j.jep.2012.01.028

40. Verma, S., \& Singh, S. P. (2008). Current and future status of herbal medicines. Veterinary World, 1 (11), 347-350

41. Warner, S. L. (1965). Randomized response: A survey technique for eliminating evasive answer bias. Journal of the American Statistical Association, 60 (309), 63-69. https://doi.org/10.10 80/01621459.1965.10480775

42. Watson, J. J., \& Wright, K. (2000). Consumer ethnocentrism and attitudes toward domestic and foreign products. European Journal of Marketing, 34 (9/10), 1149-1166. https://doi. org $/ 10.1108 / 03090560010342520$

43. Zheng, T., Yao, D., Chen, W., Hu, H., Ung, C. O. L., \& Harnett, J. E. (2019). Healthcare providers' role regarding the safe and appropriate use of herbal products by breastfeeding mothers: A systematic literature review. Complementary therapies in clinical practice, 35 (1), $131-147$.

\section{Contact information}

Ing. Abdul Bashiru Jibril, Ph.D. Candidate

Tomas Bata University in Zlin

Faculty of Management and Economics

Department of Management and Marketing

Czech Republic

E-mail:jibril@utb.cz,mallambash13@gmail.com

ORCID: orcid.org/0000-0003-4554-0150 
Ing. Michael Adu Kwarteng, Ph.D.

Tomas Bata University in Zlín

Faculty of Management and Economics

Department of Management and Marketing

Czech Republic

E-mail:kwarteng@utb.cz.

ORCID: orcid.org/0000-0002-6787-0401

Doc Ing. Miloslava Chovancova, Ph.D.

Tomas Bata University in Zlin

Faculty of Management and Economics

Department of Management and Marketing

Czech Republic

E-mail:chovancova@utb.cz.

ORCID: orcid.org/0000-0002-9244-9563

Dr. Richard Denanyoh

Sunyani Technical University

Faculty of Business and Management

Department of Marketing

Ghana

E-mail: richarddenanyob@yahoo.com

ORCID: 0000-0002-6337-9092

\section{Appendix}

Tab. 6 - Strength of correlated variables. Source: own research

\begin{tabular}{|l|l|l|}
\hline Variable relationship & Percent & Strength of correlation \\
\hline Gender $\leftrightarrow$ usage & 11 & moderate \\
\hline Age $\leftrightarrow$ usage & 5 & weak \\
\hline Education $\leftrightarrow$ usage & 8 & weak \\
\hline Degree of processing $\leftrightarrow$ usage & 75 & Strong \\
\hline
\end{tabular}

